Fecha de recepción: 9-11-2017

Fecha de aceptación: 15-12-2017

Link para este artículo: http://dx.doi.org/10.14198/ALEUA.2018.29-30.03

Puede citar este artículo como:

Bajo Martínez, María Jesús, «José Tamayo y el TEU de Granada», Anales de Literatura Española, n. ${ }^{\circ}$ 29-30

(2018), pp. 77-96.

\title{
JOSÉ TAMAYO Y EL TEU DE GRANADA
}

\author{
MARÍA JESÚS BAJO MARTÍNEZ \\ Centro de Documentación de las Artes Escénicas de Andalucía
}

\section{Resumen}

José Tamayo, director de escena y productor teatral, fue una figura indiscutible de la escena española de la segunda mitad del siglo XX. Contribuyó a la modernización del teatro español, pero la mayor parte de las características que definirían posteriormente sus puestas en escena se encontraban ya en sus inicios como director de la compañía universitaria de su ciudad, Granada, como el uso de la iluminación, la música, un cuidado vestuario y escenografías realizadas por reconocidos artistas. Fue director del TEU de Granada desde 1944 a 1946, fecha en que la compañía de teatro Lope de Vega se hizo profesional. Durante los años en que José Tamayo dirigió este TEU, el grupo alcanzó una gran calidad artística y se situó entre las primeras compañías de Teatro Español Universitario del país.

Palabras clave: José Tamayo; Teatro Español Universitario; TEU; teatro y universidad; teatro en Granada; Universidad de Granada; teatro en los años cuarenta.

\begin{abstract}
José Tamayo, stage manager and theatrical producer was an undisputed figure of the Spanish scene during the second half of the XX Century. He contributed to the renewal of Spanish theater. But most of the characteristics that lately would define his work could be found on his beginnings as a director of the university company of his native city, Granada, like the use of the illumination, the music, and amazing wardrove and scenographies made by wellknown artists. He was the director of the Granada TEU since 1944 to 1946, when the theater company Lope de Vega became professional. During the years José Tamayo directed that TEU, it reached a high artistic quality and it positioned itself on the top list of Spanish Academic Theater companies of the country.
\end{abstract}

Keywords: José Tamayo; Spanish Academic Theater; TEU; theater and university; theater in Granada; Granada University; theater on the 40s.

Anales, 29-30 (2018), pp. 77-96

DOI: 10.14198/ALEUA.2018.29-30.03 
José Tamayo fue director de escena, productor y empresario teatral. Su compañía fue titular del Teatro Fuencarral. En 1949 emprendió una gira por América que le llevó durante dos años a realizar mil doscientas representaciones en cincuenta y dos ciudades diferentes. Dirigió el Teatro Español de 1954 a 1962, y solamente en estos años estrenó cuarenta obras. En 1961, inauguró el Teatro Bellas Artes de Madrid y años más tarde el Nuevo Apolo. Fundó la compañía lírica Amadeo Vives. Fue titular del Teatro Lírico Nacional y realizó una importante labor de difusión del teatro lírico español. Sus diferentes antologías de la zarzuela, que en ocasiones contaron con un elenco que superaba los cien artistas en escena, se pudieron ver a lo largo de sus varias décadas en más de cien países de los cinco continentes y alcanzaron la cifra de diecisiete millones de espectadores. Revitalizó la escena española de los años cincuenta renovando el concepto de espectáculo. Y, pese a algunas matizaciones que se le pueden hacer - y que muy bien precisa César Oliva en su artículo del número de la ADE dedicado a Tamayo tras su fallecimiento (2003: 20-21)—, dio a conocer al gran público a autores extranjeros como Brecht o Bernanos y devolvió a las tablas de los teatros comerciales a autores nacionales como Valle-Inclán o Lorca. Llevó el teatro clásico español a Nueva York y Washington, así como a numerosas ciudades europeas. Descubrió a grandes actores y con él trabajaron los más famosos intérpretes del país. Contribuyó a la recuperación del teatro romano de Mérida para la escena. Entre sus numerosos reconocimientos destacan la Medalla de Oro al Mérito en las Bellas Artes (1991), las encomiendas de Isabel la Católica y Alfonso X, la Primera Estrella de la Comunidad de Madrid por su labor artística y cultural en la historia de la escena española, el premio Los Mayores del Año 1997, el premio Mayte de Teatro (1997) y el Max de honor por toda su trayectoria (2002). Como se puede apreciar, el de Tamayo es un nombre imprescindible en el panorama escénico nacional de la segunda mitad del siglo XX.

Pero ¿cómo se inicia la vida escénica de Tamayo? José Tamayo Rivas nace en Granada el 16 de agosto de 1920, en el seno de una familia humilde. Ingresa en el seminario menor, donde entra en contacto con los clásicos y conoce la obra de José M. ${ }^{a}$ Pemán El divino impaciente, que le impresionó vivamente. En esta época comienza a hacer teatro. Uno de sus papeles más recordados fue el chinito Chao, en el drama misional Chao, del jesuita Juan Lamamié de Clairac, ${ }^{1}$ aunque lo desempeñó con escasa fortuna y casi provoca un incendio en el escenario con una lámpara de petróleo. Estas experiencias, junto con

1. Chao es un drama lírico en cuatro actos para público infantil compuesto por Juan Lamamié de Clairac y música de Vicente Arregui. De temática misional, está dedicado a los socios de la obra de Los Doce Apóstoles. 


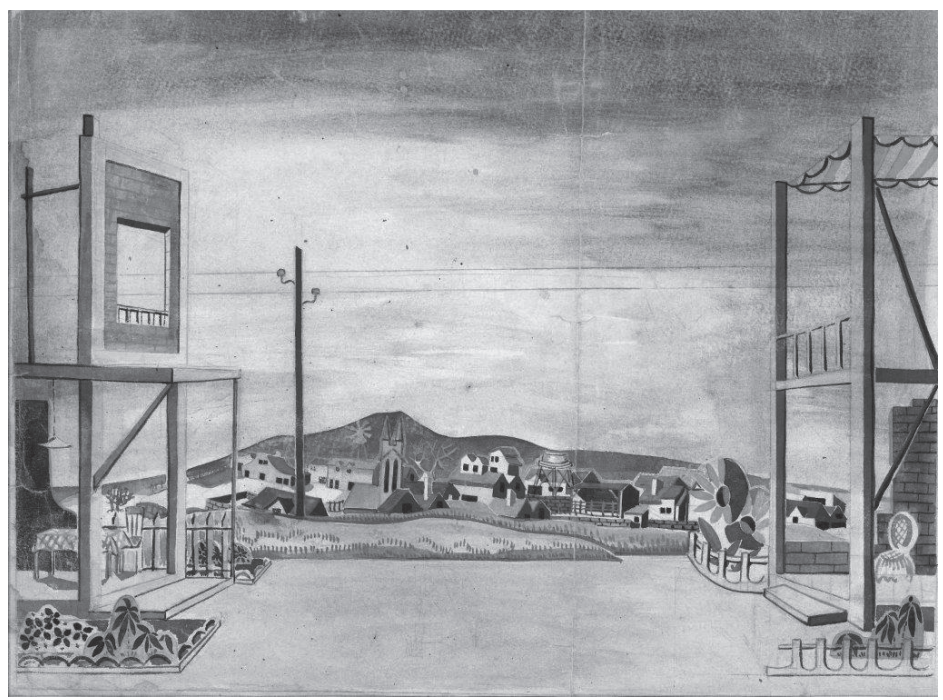

la impresión que le causó el primer espectáculo profesional al que asistió, $\mathrm{La}$ verbena de la Paloma interpretada por Miguel Fleta, parecen estar en el origen de su vocación escénica. Tras su paso por el seminario, estudió en la Escuela de Comercio. Durante la Guerra Civil sirvió en la escuela de aviación. Al finalizar la contienda trabajó en la administración de un periódico. Pero su pasión por el teatro permaneció indemne. A partir de 1937 se dedicó, junto a otros jóvenes, a representar obras de teatro al aire libre, fundamentalmente entremeses y pasos de Lope de Rueda, Juan del Enzina y Cervantes.

Y así, en 1937, con motivo del día de las misiones, podemos encontrarlo representando nuevamente la obra Chao en el salón de los Estanislaos, ${ }^{2}$ en esta ocasión interpretando el papel del padre Carlos. A decir de la prensa, fue muy aplaudido.

En 1941 lo volveremos a encontrar interpretando el papel de Alhamar en El Alcázar de las perlas, de Villaespesa, en el Teatro Cervantes, con la Sección de Teatro de Educación y Descanso. Ya en 1942, en las fiestas del Corpus aparece como realizador de La estrella de Sevilla, de Lope de Vega, en el palacio de Santo Domingo. El director era Manuel Hernández y la agrupación pertenecía al Frente de Juventudes. También en 1942, aparece vinculado a la puesta en escena de El médico simple, de Lope de Rueda. Nuevamente aparecerá como realizador de los espectáculos programados por el Frente de Juventudes para

2. Organización de alumnos de segunda enseñanza de los jesuitas.

Anales, 29-30 (2018), pp. 77-96 
el Corpus del año 1943, en el palacio de Santo Domingo: auto sacramental de El gran teatro del mundo, de Calderón de la Barca, y Luz de amanecer, de Manuel Benítez. ${ }^{3}$ En esta ocasión figura como director Emilio Prieto. Ya en estas representaciones aparecen algunos de los nombres que formarán parte del elenco del TEU de Tamayo.

Y tras este periodo inicial llegamos a 1944, año a partir del cual figurará siempre como director, tanto de los espectáculos como de la compañía de la que formaba parte. La fecha de inicio de su labor al frente del TEU de la Universidad de Granada no es precisa, aunque todo parece indicar, según se refleja en diferentes programas y entrevistas, que fue 1944, a pesar de que en algunos artículos de prensa y programas de mano se adelanta hasta el inicio de la década. Según los datos recabados, la presentación oficial de la compañía Lope de Vega parece que se realizó en abril de 1944, en el Teatro Cervantes:

Para la presentación del Teatro Lope de Vega, nueva agrupación de Educación y Descanso, se ha elegido la comedia de arte dramático La amada eterna, original del autor novel Abel Zarco. El conjunto artístico lo dirige el realizador José Tamayo, que cuenta con un gran plantel de buenas figuras. Los decorados de la obra, de Torres Labrot, son magníficos, así como el vestuario, lo que hará sin duda que la comedia constituya un verdadero éxito (La Prensa, 1944: 4).

Como se puede apreciar, está directamente asociada a Educación y Descanso, organismo que en esos momentos sufragaba a distintos TEU a lo largo del país. En otras ocasiones se la denomina simplemente como Teatro Lope de Vega. Será a partir de 1945 cuando aparezca habitualmente como Teatro Universitario Lope de Vega. Esta denominación vacilante contribuye a la confusión de su origen. El propio Tamayo se refiere a los TEU como Teatros Juveniles y reconoce que «el Teatro Lope de Vega granadino inició sus trabajos con la protección del Frente de Juventudes» (Ibid.). Por otra parte, este hecho no hace más que presentar una evolución lógica y de dependencia de la situación político-escénica del momento. Incluso en ocasiones se ha llegado a decir que con José Tamayo surgió el TEU de Granada, hecho totalmente incierto.

3. Manuel Benítez Carrasco (Granada, 1922-1999). Poeta y rapsoda. Escribió dos obras de teatro en su juventud: Luz de amanecer, que obtuvo el Premio Nacional de Teatro de Escuadra en 1943, y Castillo de Dios, un auto sacramental. El teatro de escuadra se denominaba así por estar formado por cinco jóvenes y un mando. En cada provincia se daba un tema para su desarrollo, y se competía entre los distintos sectores provinciales hasta llegar a la final. 


\section{TEU de Granada}

En plena Guerra Civil, y como en otras ciudades españolas, en Granada surge un teatro promovido por el SEU. En estos primeros momentos la denominación aún no está clara y alternan nombres como Cuadro Artístico del Sindicato Español Universitario y Teatro Español Universitario. Su politización es más que evidente al ver los programas de mano, que como otros muchos del momento están cargados de alusiones propagandísticas. Al igual que en otros TEU de la época, y en íntima relación con el público al que va dirigido — soldados convalecientes y sufridores de la guerra en general-, alterna el teatro clásico, especialmente entremeses y pasos de Cervantes y Lope de Rueda, con juguetes cómicos más próximos en el tiempo, de autores como los hermanos Álvarez Quintero, Muñoz Seca, Pérez Fernández y Paradas y Jiménez. Completaban el programa recitales de poesía o verbenas.

En junio de 1939 nos encontramos con un TEU de Granada consolidado, que participa junto con los de Córdoba, Cádiz, Huelva, Málaga y Sevilla en la Gran Semana del SEU de Andalucía, celebrada del 11 al 18 de junio en Sevilla. El programa que presentó el TEU de Granada en el Teatro Llorens fue La guarda cuidadosa, de Cervantes, y Las aceitunas y El médico simple, de Lope de Rueda. Durante estos difíciles años dirigen el TEU de Granada Alfonso Aragón y Arturo Sierra.

Como se puede apreciar, cuando Tamayo se hace cargo del TEU, éste ya tenía una trayectoria similar a otros TEU, pero lo que sí es cierto es que el grupo llevaba unos años de letargo y realizando puestas en escena muy ocasionales, como la de 1941 con motivo de la festividad de santo Tomás de Aquino, en que escenificó la estampa de Gómez Manrique Representación del Nacimiento de Nuestro Señor en el Palacio de Santo Domingo.

Durante su etapa al frente del TEU de Granada, José Tamayo estuvo asesorado por Cayetano Luca de Tena, Antonio Gallego Burín ${ }^{4}$ y Rafael Baquera Álvarez ${ }^{5}$, que ostentaban el cargo de directores honorarios y, como tales, contribuían al desarrollo de la compañía. Gallego Burín, en esos momentos alcalde de la ciudad, patrocinó diferentes puestas en escena, así como la gira que realizó

4. Antonio Gallego Burín (Granada, 1895- Madrid, 1961) fue periodista y catedrático de Historia del Arte de la Universidad de Granada. Ocupó la alcaldía de Granada en los periodos 1938-1940 y 1941-1951. Desempeñó el cargo de gobernador civil de la provincia de Granada de 1940 hasta 1941. En 1951 fue nombrado director general de Bellas Artes. Creó el Festival Internacional de Música y Danza de Granada.

5. Rafael Baquera Álvarez (1895- Madrid, 1973) fue general de brigada del arma de aviación y vocal del Consejo Directivo del Patronato de Casas del Ramo del Aire. A principios de los años cuarenta era coronel de aviación. 


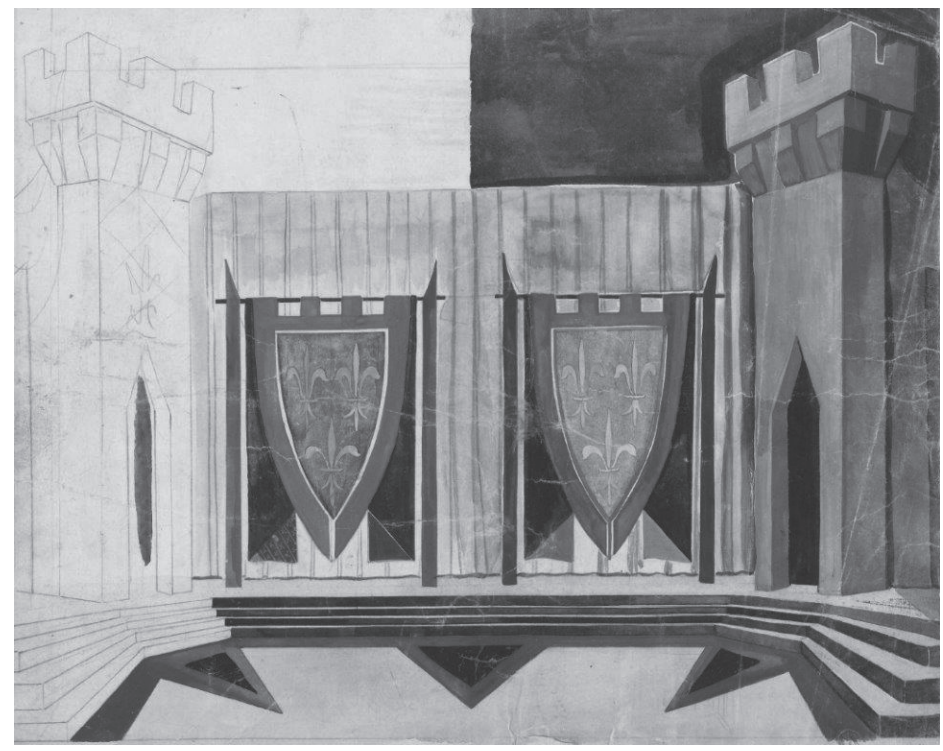

el TEU granadino por diversas ciudades del norte de África durante la Navidad de 1945. Tamayo siempre recordó este apoyo: «Mis primeros pasos en el TEU, que luego germinó en la compañía Lope de Vega, se dieron gracias al estímulo que siempre recibió del Ayuntamiento granadino y del alcalde Antonio Gallego Burín» (Saiz-Pardo, 1997).

Con un nutrido grupo de actores consiguió, y digo consiguió porque en el teatro universitario está demostrado que el director es el elemento de cohesión y de pervivencia de un grupo heterogéneo y de paso, una de las agrupaciones teatrales universitarias más prestigiosa de la década. ${ }^{6}$

6. Esta lista de actores es bastante exhaustiva, aunque sin duda faltará alguno: María Olóriz, Lucrecia Moral, Lily Corral, Elisa Coca, Alicia Navarro, Blanca López Luque, Conchita López Jurado, Isabel Peñuelas, Elia Villanova, María Leticia Cuadrado, María Luisa López Jurado, Dolores de la Higuera, María Victoria Olmedo, María Fernanda Rubio, Emilia Peñuelas, María Luisa Cabrera, María del Carmen M. de Villena, Conchita Girón, Araceli Pelsmaeckers, Natividad Márquez, María Méndez, Jesusa Toro, Anita Porras, Carmen Figueruela, Pepita López, Mari Pepa Arredondo, Rosita Sanchiz, Mercedes Ruiz, Conchita Arredondo, Elena Soler, Avelino Cánovas, José Sánchez, Manuel Soler, Emilio Prieto, Rafael Santamaría, Mauricio Gómez, Pedro Gollonet, Ramón Moreno, Luis Salcedo, Antonio Marín, Rafael F. Guerrero, Francisco R. Losada, Manuel F. Guerrero, José Cánovas, Miguel Ramos, Fernando Crovetto, Manuel Benítez, Manuel G. Sánchez Reina, Miguel F. Quintián, Miguel de la Rosa, José G. Borrás, Andrés Sánchez, Miguel Fernández, Francisco Roca, Francisco Palma, Manuel Gallego, Francisco Cano, Juan Castillo, José Luis Olóriz, Andrés Román, Luis G. Ponte, José G. Borrás, Joaquín López 
Para la consecución de sus fines, Tamayo creó una estructura bien definida de la que carecían otras compañías universitarias. Dividió las funciones en una dirección administrativa y otra artística, y sus miembros debían pertenecer al menos a una de ellas. La estructura es la siguiente (Tamayo, 1944): «Dirección del Teatro: Organización, administración, propaganda y asesores literarios. Dirección de Escena: Declamación, música y ballet, escenografía y vestimenta, luminotecnia y ayudante de dirección».

Lo elevado del número de montajes no se corresponde con lo escaso de las representaciones. El número de representaciones se incrementaba cuando salían a representar a otras localidades. Las limitadas puestas en escena de un mismo título era lo habitual en los TEU, y al igual que ellos, también las escenificaciones estaban muy relacionadas con las conmemoraciones de la ciudad, en este caso la celebración del Corpus, fiesta grande de Granada, o académicas como las representaciones organizadas por los alumnos de Derecho canónico como homenaje a Andrés Manjón. ${ }^{7}$ Con motivo de este homenaje se llevó a escena Nuestra ciudad, de Thorton Wilder, en 1946, y el estreno de El divino impaciente, de José María Pemán, se hizo en un pase de mañana exclusivamente para estudiantes universitarios en la Gran Semana Misional. Una semana más tarde se volvió a representar en funciones de tarde y noche. Igualmente colaboró con proyectos solidarios, como la recaudación de fondos para la creación de un dispensario de Cruz Roja con la puesta en escena de El mercader de Venecia, de Shakespeare. Para beneficio de este cuerpo de auxilio ya había actuado anteriormente con la representación de Baile en Capitanía, de Agustín de Foxá.

De entre sus salidas fuera de la ciudad destaca la gira realizada del 26 de diciembre de 1945 al 9 de enero de 1946 por Ceuta, Tetuán y Tánger, y a la vuelta Gibraltar. Promovió la gira Luis Seco de Lucena, director de la Escuela de Estudios Árabes, y las obras que pusieron en escena fueron María Estuardo, de Schiller, y Don Juan Tenorio, de Zorrilla, para lo cual contaron con la participación de las actrices profesionales Maruchi Fresno y Mariana Larrabeiti. Acompañaron al grupo los escenógrafos y figurinistas Francisco Torres Labrot y Antonio Moscoso. Las actuaciones levantaron gran expectación

Sáez, Joaquín de Andrada, Gonzalo Fernández de Córdoba, Miguel Rodríguez Acosta, Luis Múller, Fernando Monsalve, Luis Hernández y Eduardo Ferrer.

7. Andrés Manjón (Sargentes de la Lora, Burgos, 1846-Granada, 1923). Catedrático de Derecho Romano en la Universidad de Salamanca y de Disciplina Eclesiástica en la Universidad de Santiago, y desde 1880 ocupó la misma cátedra en Granada. Posteriormente impartió derecho canónico. Se ordenó sacerdote en 1885 y fundó las escuelas del Ave María. 
en las diferentes localidades, y se siguieron con interés en la prensa granadina y en el Diario de África.

El SEU se financiaba con las cuotas de los afiliados y con las contribuciones voluntarias de los socios protectores. A partir de 1943, la cuota, con la afiliación obligatoria de todos los estudiantes, era de tres pesetas al mes. Sin duda esta cantidad era insuficiente para afrontar las diferentes actividades del SEU. Una buena forma de solventar la falta de recursos económicos, pues la taquilla de dos o tres funciones no bastaba para cubrir los gastos de los espectáculos, era recurrir al patrocinio. El TEU de Granada - y en general todos los TEUaceptaba el patrocinio de instituciones públicas y en ocasiones privadas, como la Asociación de la Prensa, que contribuyó a la producción de Romeo y Julieta y Sueño de una noche de verano (que costó nada menos que doce mil duros, como informó la prensa), de Shakespeare, y Don Juan Tenorio, de Zorrilla. En el caso del TEU de Tamayo, y como premio a su buen hacer, contaba con la financiación del Ayuntamiento, especialmente en la festividad del Corpus, y del Gobernador Civil y Jefe Provincial del Movimiento, además del Frente de Juventudes y Educación y Descanso en sus inicios.

Las representaciones se hacían habitualmente en el Teatro Cervantes, aunque las puestas en escena con motivo del Corpus se realizaban en el magnífico patio del palacio de Carlos V, en la Alhambra. Estos casos fueron La vida es sueño, en 1944, Romeo y Julieta, en 1945, y Sueño de una noche de verano, en 1946. Este último año también representaron en las gradas de la catedral (plaza de las Pasiegas, por entonces recién reformada) El gran teatro del mundo. Este mismo espacio lo retomaría años más tarde otro director del TEU granadino, José Martín Recuerda. Los espacios de ensayo eran más variados, y lo mismo transcurrían en la Casa de los Tiros, como en la propia Universidad.

\section{Repertorio}

El TEU de Granada llevó a escena en este periodo las siguientes obras:

\section{4}

- La amada eterna, de Abel Zarco. Estrenada el 26 de abril con escenografía de Torres Labrot.

- La vida es sueño, de Calderón. Estrenada durante las fiestas del Corpus con escenografía de Torres Labrot y Emilio Burgos.

- Baile en Capitanía, de Agustín de Foxá. Estrenada el 29 de noviembre con escenografía de Torres Labrot y coreografía de Miguel del Castillo. 


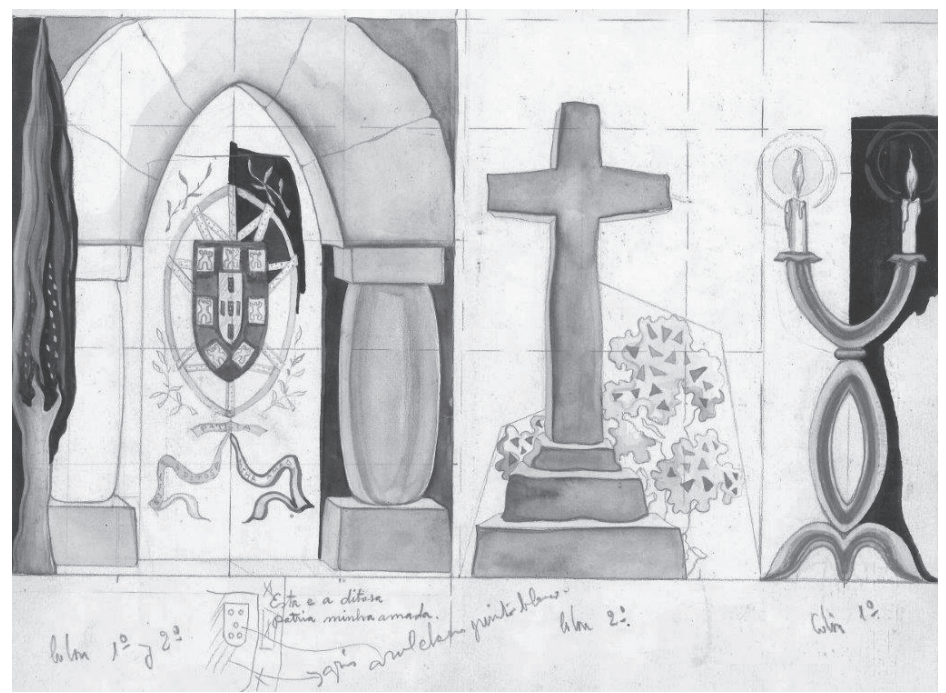

1945

- El divino impaciente, de Pemán. Estrenada el 21 de enero con escenografía de Torres Labrot.

- María Estuardo, de Schiller. Estrenada el 13 de marzo con escenografía de Torres Labrot y figurines de Antonio Moscoso. La dirección de orquesta y coros corrió a cargo de Ruiz Aznar.

- Romeo y Julieta, de Shakespeare. Estrenada el 1 de junio con escenografía de Torres Labrot y figurines de Antonio Moscoso

- Don Juan Tenorio, de Zorrilla. Estrenada el 1 de noviembre con escenografía de Torres Labrot y figurines de Antonio Moscoso.

1946

- Nuestra ciudad, de Thorton Wilder. Estrenada el 12 de febrero con escenografía de Torres Labrot.

- El mercader de Venecia, de Shakespeare. Estrenada el 29 de mayo con escenografía y figurines de Emilio Burgos y Vicente Viudes.

- El gran teatro del mundo, de Calderón. Estrenada en junio con escenografía y figurines de Torres Labrot.

- Sueño de una noche de verano, de Shakespeare. Estrenada el 21 de junio con escenografía de Torres Labrot.

Felipe Higuera (1991: 181-199) incluye entre los montajes de Tamayo de estos años las siguiente obras: Misterio de Navidad (1944), El vergonzoso en palacio, 
de Tirso (1944), En Flandes se ha puesto el sol, de Marquina (1944), La estrella de Sevilla, de Lope de Vega (1944), Luz de amanecer, de Manuel Benítez (1945) y El alcázar de las perlas, de Villaespesa (1945), aunque hasta el momento no se han podido localizar en estas fechas datos sobre dichas puestas en escena relacionadas con el TEU, pero como se ha expuesto anteriormente, algunas de ellas sí fueron realizadas por José Tamayo en etapas anteriores. En cambio, el listado de Higuera no recoge El mercader de Venecia.

La misión de Tamayo era aunar la pasión teatral con la visión falangista que imponía el hecho de pertenecer al TEU. Tarea nada fácil, pero no imposible para un hombre que siempre practicó el posibilismo en su carrera. El principal objetivo que se había marcado lo expresaba así en una entrevista de 1945: «Nuestro Teatro Universitario tiene el propósito de dar exactas interpretaciones al teatro clásico español y universal y una labor constante de perfeccionamiento ha conseguido resultados magníficos» (La Prensa, 1945: 6).

El TEU de Granada de los años cuarenta coincide con las ideas generales del teatro de Falange. Su repertorio, como acabamos de ver, está compuesto por numerosas obras del acervo clásico español, que se consideraba como la máxima expresión del espíritu nacional, y la más apta para, además de educar escénicamente al público, transmitir los nuevos ideales del Estado nacionalcatólico y su visión de la Hispanidad.

No obstante, José Tamayo sin salirse de los cauces establecidos representa una visión personal del tema ya desde el principio, pues la mayoría de los TEU se conformaban con llamarse simplemente TEU de la ciudad en cuestión, frente al de Tamayo que se denominaba Teatro Universitario Lope de Vega. «Escogí el nombre de Lope de Vega porque él representaba para mí la audacia, la altura, lo popular y la fertilidad creativa» (Jarque, 1985). Como podemos observar, ninguno de los motivos de la elección responde a los principales cometidos que para el teatro tenía reservado Falange. Efectivamente, la elección resulta poco ortodoxa, pues a pesar de ser un clásico y estar bien visto, Lope de Vega no era el más representado en esta época por los universitarios, que preferían a Calderón. Por ejemplo, el TEU de Sevilla estrenó en 1940 El caballero de Olmedo, de Lope de Vega, y aunque se repuso en varias ocasiones, no volvió a estrenar otro título de este autor hasta 1953, El arenal de Sevilla. Algunos TEU eran menos proclives a llevar comedias a las tablas, frente a Tamayo, que lo hizo tempranamente y con cierta asiduidad.

Tamayo puso en escena los autos sacramentales El gran teatro del mundo, de Calderón, y el contemporáneo, Luz de amanecer, del granadino Manuel Benítez. Hay que recordar la estrecha relación del Teatro de Falange con este género. El 14 de junio de 1938, desde Burgos se da la orden por la cual «Se 
establece la conmemoración teatral del Corpus Christi y se confía la misma al Departamento de Teatro del Servicio Nacional de Propaganda» (BOE, 1938). Desde ese momento, los teatros juveniles y universitarios incluyeron discrecionalmente los olvidados autos en sus repertorios.

En otra línea bien distinta, este joven director comienza a introducir a algunos autores extranjeros poco usuales, no ya en la cartelera universitaria, sino en la comercial, como Thorton Wilder, que en ese momento se consideraba como el ejemplo de la futura dramaturgia, y muy especialmente a Shakespeare, gran favorito de Tamayo. Durante la primera mitad de la década de los cuarenta los dramaturgos extranjeros más representados son los clásicos de países con una ideología afín a la imperante en la España del momento como Goethe, Schiller, Goldoni o Almeida Garret. Igualmente, introduce muy tempranamente en comparación con otros grupos, a contemporáneos como Pemán y Agustín de Foxá, ambos afectos al nuevo régimen.

Hay que aclarar que la elección de Wilder y Foxá no es casual, ya que, en la temporada anterior, el primero había conseguido un éxito arrollador en el María Guerrero, y otro tanto se puede decir del segundo y de su representación, meses antes, en el Teatro Español. La decisión de llevar a las tablas Nuestra ciudad fue muy bien acogida, "Nuestra ciudad ha venido a colmar nuestra sed de teatro nuevo» (Tamayo, 1946, p. 4), lo que parece reflejar que existía, al menos en parte del público, un deseo de disfrutar y conocer un teatro diferente, como expresó el crítico del Ideal:

El numeroso y selecto público que asistió ayer a la representación de Nuestra ciudad, en el Teatro Cervantes, se vio sorprendido por el género teatral nuevo, original, muy variado de matices en la acción y, en suma, digno de recibirlo bien por cuanto nos ofrece de novedad y halagadora esperanza en el rutinario arte escénico (1946: 7).

Y todo ello a pesar de que el propio director consideraba la obra complicada para actores y público, como se desprende de sus palabras en el programa de mano: «Obra, pues, no para los públicos fáciles del realismo teatral y del latiguillo poético. Obra aún más difícil en su escenificación para el actor manido y el aficionado vulgar».

Pero más innovadora aun es la potenciación de jóvenes autores como Abel Zarco. En relación a esta última cuestión, Tamayo tenía las ideas muy claras acerca de cuál debía ser la misión de un TEU: «Los Teatros Juveniles llevarán a nuestros escenarios de provincia las mejores obras que se estrenen en España y acortarán el difícil camino de esa masa de autores noveles que en Madrid asalta los despachos de los directores, inútilmente» (1944). 


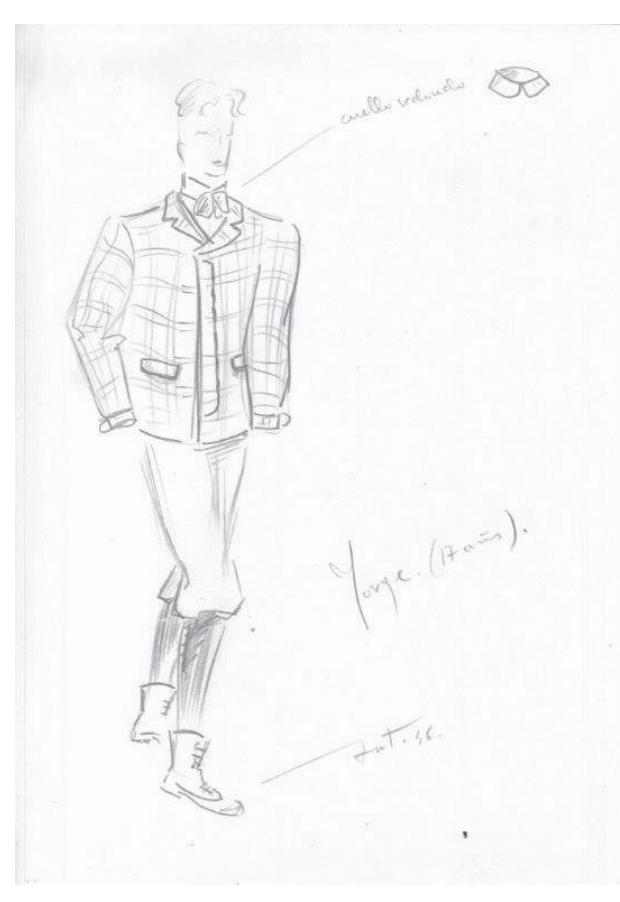

La visión de este director de escena del papel a desempeñar por los TEU es meridiana: renovar la cartelera con espectáculos de calidad ya estrenados en Madrid y dar oportunidad a los jóvenes autores. Su modelo a seguir será el TEU Nacional, que en esa época dirigía el jienense Modesto Higueras, antiguo miembro de la Barraca, que inicia su actividad en el TEU a principios de la década y abandona el cargo de director en 1951. Durante su dirección, el TEU Nacional se caracterizó por llevar a escena espectáculos de calidad elevada y alejados del teatro casual de aficionados. Otra influencia definitiva en Tamayo es la de los Teatros Nacionales, como se ha manifestado. Luis Escobar y Huberto Pérez de la Ossa dirigían el María Guerrero, y Cayetano Luca de Tena, el Español. La relación de Tamayo con estos directores fue muy estrecha, especialmente con Luca de Tena, quien se desplazó a Granada para supervisar los montajes de La vida es sueño y Romeo y Julieta, cedió el vestuario del Teatro Español para los montajes de Baile en capitanía y Romeo y Julieta, y también para esta obra seleccionó como protagonista a la primera actriz Mari Carmen Díaz de Mendoza. Por su parte, José Tamayo ya entonces, y posteriormente, reconocía lo positivo de esta tutela. En 1945 se refería así a Luca de Tena: «Es uno de los mejores realizadores de España. Es un decidido protector de nuestro 
teatro universitario y siempre nos ha dado muestras de gran interés por nuestra labor» (La Prensa, 1945: 6).

Como prueba de esta influencia debe destacarse que, en la época que estudiamos, es mínimo el número de títulos del amplio repertorio de este TEU que no hubieran sido estrenados anteriormente por el Teatro de las Organizaciones Juveniles, el TEU Nacional de Modesto Higueras, el Teatro María Guerrero o el Español.

\section{Puesta en escena}

Para conseguir su objetivo, la renovación de la depauperada escena española, había que utilizar todos los procedimientos al alcance: textos modélicos, escenarios naturales, innovaciones técnicas e incorporación de otros elementos artísticos, y todo ello para recrear un teatro grandioso y nacional.

La transformación en realidad del teatro soñado por Falange se había materializado el día de la festividad del Corpus Christi de 1938, cuando delante de la catedral de Segovia se escenificó el auto El hospital de los locos, de José de Valdivielso. Como es sabido, el montaje se realizó bajo la dirección de Luis Escobar, con diseños de Pedro Pruna y música de Arambarri. Actuaron el cabildo de la catedral y más de ciento cincuenta actores, incluidos los figurantes. Los más ricos ornamentos y ropas de la catedral se incorporaron al montaje. Este espectáculo, que se repitió en otras ciudades, además de un hito, marcó toda una línea y estableció una estética, especialmente en los espectáculos al aire libre, y ninguno como José Tamayo para plasmar esta magnificencia.

José Tamayo, ya desde su primera época, como director cuidaba minuciosamente la puesta en escena. Superaba las expectativas de cualquier TEU que no fuera el nacional, sus escenógrafos y figurinistas, lejos de ser como en el resto de los TEU compañeros de Bellas Artes, eran auténticos profesionales, como el pintor granadino que tanto colaboró con él en esta primera etapa, Francisco Torres Labrot, el reconocido Emilio Burgos o el creador también granadino Antonio Moscoso. Prestaba especial atención a la escenografía y no dudaba en encargar las estatuas del panteón de los Tenorio al escultor granadino Navarro Díaz. El vestuario en esta época ya representaba para el director un elemento fundamental, y bien se trasladaba personalmente a Madrid para conseguirlo en préstamo del Teatro Español, bien se encargaba íntegramente su confección. Para la puesta en escena de Sueño de una noche de verano se realizó íntegramente en Madrid el vestuario diseñado por Torres Labrot, cincuenta trajes en terciopelo y raso creados expresamente para las dos funciones realizadas durante la festividad del Corpus en Granada. El mismo Tamayo habló en su momento sobre el nuevo vestuario de Don Juan Tenorio: 
Es garantía de éxito el haber confiado los figurines de los trajes a Moscoso y Torres Labrot, jóvenes artistas con una visión muy clara de la indumentaria en el teatro. En el montaje vamos a echar, como vulgarmente se dice, la casa por la ventana. Mallas, gorros y hasta el calzado, han sido confeccionados para completar hasta en el menor detalle el porte de los personajes de la obra (Ibid.).

Con el mismo esmero seleccionaba a los directores musicales y coreógrafos. Llegó a encargar composiciones originales para las puestas en escena, como las solicitadas al maestro Manuel Parada para Sueño de una noche de verano o El gran teatro del mundo. Lo mismo sucedía con las adaptaciones del crítico y estudioso Nicolás González Ruiz, ${ }^{8}$ sus preferidas a la hora de enfrentarse a un clásico.

Recurrió con mucha frecuencia a actores profesionales y de conocido prestigio para los papeles protagonistas como recurso para reclamar la atención del público, además de dar mayor brillantez al montaje. Estos actores fueron: Blanca de Silos, Rosita Yarza y José M. a Seoane en La vida es sueño; Amparo Reyes y Maruchi Fresno en María Estuardo; Mari Carmen Díaz de Mendoza, Fernando Rey y María Larrabeiti en Romeo y Julieta; Maruchi Fresno y María Llarrabeiti en Don Juan Tenorio; Rosita Yarza en Nuestra ciudad; Mercedes Prendes en El mercader de Venecia; M. ${ }^{a}$ Asunción Balaguer y Maruchi Fresno en El gran teatro del mundo, que repiten experiencia junto a Carmen de Lucio en Sueño de un anoche de verano. Maruchi Fresno, la actriz que más colaboró con estos estudiantes del TEU, consideró la experiencia muy positiva: «Todos eran estudiantes, y todos estuvieron maravillosamente. Pero he de hacer mención especial del Don Juan, un estudiante malagueño, José Sánchez. Ojos azules y unas grandes condiciones de actor... Fuimos dirigidos estupendamente por José Tamayo, un director muy joven, que tiene una modernísima y perfecta visión del buen teatro (Juanes, 1946).

Tamayo, un autodidacto con gran instinto para la escena, cuidaba a los actores y se dejaba sorprender por ellos. Su dirección no temía a la innovación, como explicó años más tarde: «Esos nuevos caminos los busqué ejercitando el teatro sobre el escenario, y frente al público, y aprendiendo de los grandes actores, a los que después conduje por formas casi nuevas para ellos y en las que yo creía (Serna, 1996: 50-83).

Y de este modo, en los primeros años cuarenta, era capaz de sorprender con su propuesta de la más que conocida escena del sofá de Don Juan Tenorio a

8. Nicolás González Ruiz (Mataró, 1897-Madrid, 1967). Escritor, crítico literario y periodista. Fue profesor adjunto de lengua y literatura en la Universidad de Liverpool. Realizó numerosas adaptaciones y traducciones de textos dramáticos, así como estudios críticos sobre teatro español. 


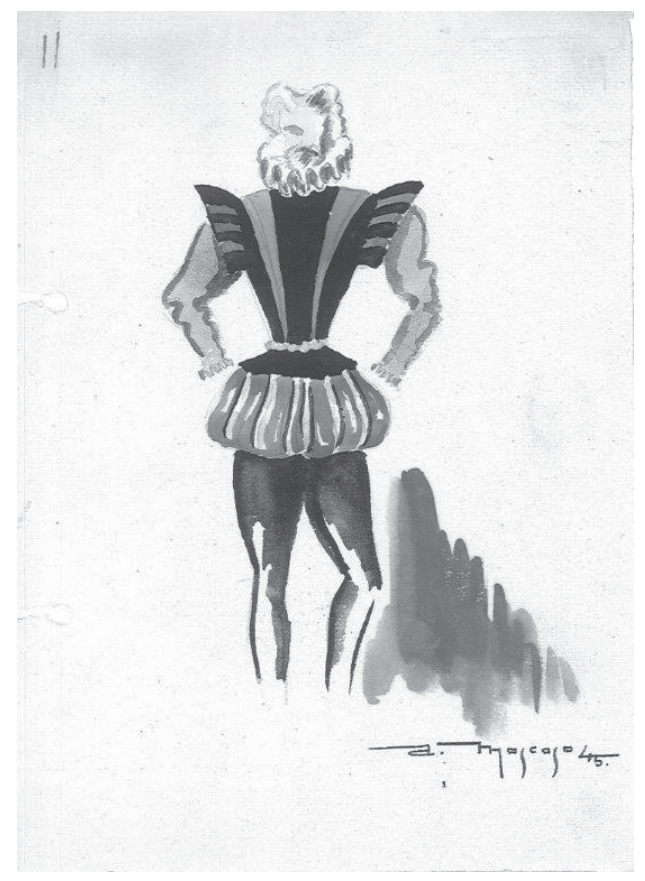

unos espectadores que casi se la sabían de memoria: «Esta clásica escena de sofá no debe tener de sofá sino la mitad. La mitad primera ha de ser representada como ayer, en pie los actores y de espaldas al público. Así lo comprendió el público, que premió con una clamorosa ovación» (Ideal, 1945: 5).

Utilizaba los recursos técnicos más innovadores, dentro de sus posibilidades, y ya entonces destacaba su personal utilización de la luz en escena, que con los años resultaría tan característica, y de la que afirmaba «la escenografía es la luz. Lo demás son aditamentos de los que se puede prescindir» (Jarque, 1985). Esta novedad no pasó inadvertida para la crítica, de la que se hacía eco ampliamente y siempre en términos elogiosos, como en el estreno de Romeo y Julieta en junio de 1945, montaje que, debido a su complejidad y características, supuso un punto de inflexión en la trayectoria de la compañía. Al espectáculo asistieron cuatro mil espectadores.

Éxito de realización por encima de todo, sería el más justo calificativo. Una perfecta instalación luminotécnica dio a cada instante el matiz apetecido y hacía variar de situación los mismos lugares que unas veces se convertían en plaza de Verona y otras en jardín o panteón de los Capuletos. En esta técnica tan sencilla y noble a un tiempo reside el mayor acierto para esta 
representación al aire libre de una obra que en un teatro cerrado necesitaría más de veinte mutaciones (La Prensa, 1945: 6).

Durante estos años, el responsable de la luminotecnia era habitualmente el experto Moral Vilches. La luz, el vestuario y la música, envueltos en una escenografía pensada para sorprender al espectador, eran los pilares fundamentales sobre los que asentaba sus creaciones. La combinación de estos elementos hacía de sus representaciones espectáculos fuera de lo común, de una poderosa seducción, especialmente los desarrollados al aire libre, donde la imaginación del director se desbordaba, como se puede apreciar en la explicación realizada por el propio director de la escenografía de Romeo y Julieta:

Se amoldará, naturalmente, a la construcción del Palacio de Carlos V y con la máxima sencillez en cuanto a escenografía pintada y con el intento de dar la mayor naturalidad a la escena, con aprovechamiento de escenografía natural que ofrece aquel recinto. Un tablado de grandes proporciones, dividido en varios planos y en ellos acoplados los diferentes decorados (Ibid.).

Tempranamente se observa su capacidad para mover en escena de forma natural e integrada a un importante número de actores y figurantes. Como ejemplos, hay que comentar que en Sueño de una noche de verano las hadas estaban representadas por el ballet, y en el caso del montaje de Romeo y Julieta contó con «un centenar de personas en escena y un cuerpo de baile compuesto por más de veinte parejas» (Ibid.), y que para la escena final de la obra colocó en la galería superior del palacio a actores con antorchas encendidas, mientras sonaba música religiosa de la época.

El público y la crítica reconocían sus esfuerzos y participaban de su entusiasmo: «El montaje es fastuoso y dice mucho de la capacidad artística de Tamayo. Este muchacho (alma del teatro Universitario) que tiene ya merecido nombre nacional» (Ideal, 1945: 5).

\section{Dignificación de la escena}

Todos estos medios y novedades iban encaminados, como ya se ha indicado, a un fin concreto. La dignificación de la escena. José Tamayo, como el resto de TEU, tenía una opinión negativa del teatro comercial: «Poco podemos esperar de las compañías profesionales que, con sus viejos trastos, hoy ruedan por los escenarios de provincias, con un teatro detestable, con unas formaciones de intereses, faltas de técnica teatral y en manos de empresarios que debieran dedicarse a otros “negocios...” ¡Esto es la negación del teatro!» (Tamayo,1944).

Igualmente, su opinión sobre las compañías de aficionados, tan abundantes en la época, era poco favorable: 


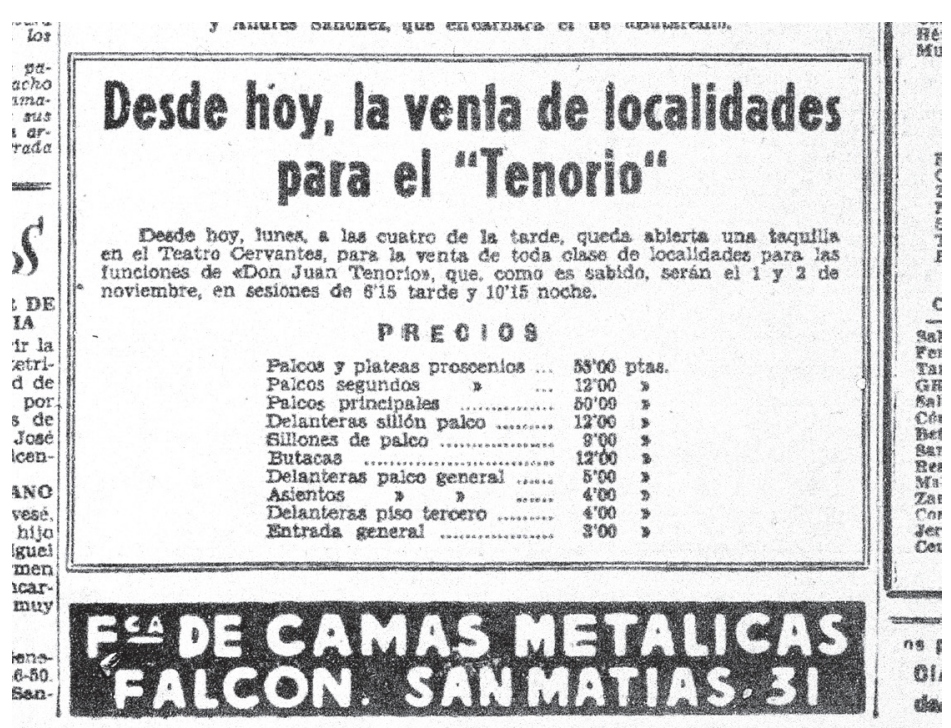

Pues bien; el «aficionado» (que ha escogido la forma de matar el tiempo haciendo teatro) enrolado en los cuadros artísticos para divertir a la gente, y continuidad en pequeña escala de esas compañías, en un acérrimo defensor del viejo teatro que éstas practican, con todos sus vicios, con la imitación acentuada del amaneramiento de sus actores, y lo peor, con una oposición declarada a lo nuevo y lo clásico, tanto en técnica como en obras (Ibid.).

Frente a la desidia y la ranciedad de la mayor parte de la escena española del momento, Tamayo, al frente de esta compañía universitaria, se entregaba por entero al teatro y se esforzaba en conseguir espectáculos de un acabado esmerado. Su profesionalidad no pasaba inadvertida, incluso para una primera figura del cine nacional como era Maruchi Fresno, que encarnó a Doña Inés en el montaje universitario:

Y puedo asegurarte que pocas veces he visto hacer teatro puro con tanto entusiasmo y acierto como en este Don Juan granadino. Han sido unas representaciones perfectas, con decorados espléndidos y novedades que acreditan un extraordinario buen gusto en su director. Como muestra de ellas, te diré que se hizo el entierro de Don Juan tras las rejas del cementerio, en una escena impresionante y grandiosa. Que las estatuas eran «de carne y hueso». Y que se poematizaron numerosos momentos con escogidos fondos musicales... Pero quizá la mayor novedad haya sido la de haberse representado el Tenorio absolutamente en serio, con una seriedad y un respeto que lo hizo doblemente grandioso (Juanes, 1946). 
Este grupo de jóvenes actores proporcionaba a la ciudad no solamente espectáculos tan buenos como los profesionales, sino que también aportaba la imaginación y la novedad tan necesarias para el sufrido público granadino. Público en el que siempre pensó y para el que trabajó a lo largo de su vida de forma incansable, como afirmaba en una entrevista con motivo de su cincuenta aniversario en la profesión: «Mi compañía y yo irrumpimos en el teatro con una idea fija, acercar las grandes obras al gran público; se ha conseguido y espero seguir consiguiéndolo, porque eso es lo que el teatro necesita hoy» (Torres, 1996).

Con su trayectoria al frente del TEU, Tamayo pone de manifiesto el importante papel de elemento renovador que el TEU ejercía en la cartelera de la época, especialmente fuera de los dos grandes centros de producción escénica del país, Madrid y Barcelona. Como ejemplo del teatro comercial que llegaba a las ciudades españolas podemos citar la cartelera del 15 de junio de 1945 en Granada, festividad del Corpus, mientras el TEU estrenaba Romeo y Julieta en el Palacio de Carlos V; en el teatro Gran Capitán, la Compañía Lírica Vázquez ponía en escena La fiesta de San Antón y La viejecita; y en el teatro Cervantes actuaba la Compañía Tina Gascó-Fernando Granada, titular del teatro Reina Victoria de Madrid, con La Escala rota y Pepa Oro.

\section{Pervivencia}

El 10 de octubre de 1946 la Compañía Lope de Vega deja de ser TEU para pasar a compañía profesional. Una vez finalizada esta etapa, se la podría considerar como un viaje iniciático, o más propiamente de estudio, en la vida profesional de Tamayo; aunque realmente no es así, porque estos años breves, pero intensos, y esa manera de hacer teatro pasarían a definir el estilo propio de este director.

Del TEU se llevó el nombre, a jóvenes actores que se profesionalizaron junto con la compañía como Avelino Cánovas, su particular concepción del papel de la luz en sus producciones, la importancia que concedía a la escenografía y al vestuario, la necesidad de rodearse de excelentes profesionales, la confianza en actores noveles, el deseo de ofrecer buen teatro por toda España, un repertorio que lo acompañó durante su primera época como compañía profesional, ${ }^{9}$ algunos títulos que se repetirían a lo largo de su carrera, ${ }^{10}$ el

9. Los títulos que formaron parte del repertorio de la recién nacida compañía profesional Lope de Vega fueron: Romeo y Julieta, Nuestra ciudad, María Estuardo, El sueño de una noche de verano y La vida es sueño.

10. A lo largo de su carrera como director de escena repuso Don Juan, La vida es sueño, El gran teatro del mundo, La estrella de Sevilla y En Flandes se ha puesto el sol. 
gusto por los clásicos convertido en una constante, sus magníficas puestas en escena de los autos sacramentales - que le llevaron a representar ante el papa Pío XII ${ }^{11}$ — y una grandiosidad difícilmente igualable en la utilización de escenarios naturales. Así pues, podríamos decir que los tres aspectos que más le interesaban en el teatro — «la inquietud, la inmensidad y el prodigio», según sus propias palabras - ya estaban presentes en el teatro que hacía en fechas tempranas con el TEU de Granada, al que, según me confesó en una entrevista, recordaba con cariño y del que siempre añoró la pasión y la entrega de sus componentes.

\section{Bibliografía citada}

BOE, 15 de junio de 1938.

Higuera, Felipe, «Cronología de los montajes dramáticos de José Tamayo», AA.VV., 50 años de teatro. José Tamayo (1941-1991), Madrid, Ministerio de Cultura, 1991, pp. 181-199.

JARQue, FietTA, «Amor a lo imposible», El País, 7 de julio de 1985.

JUANES, JOSÉ DE, «Maruchi Fresno ha debutado en el teatro», Arriba, 1 de enero de 1946.

Oliva, CÉSAR, «José Tamayo, un capítulo incompleto de la Historia del Teatro Español», ADE, 96 (2003), pp. 20-21.

SAIZ-PARDO, JUliA, «Sigo trabajando con ilusión», Ideal, 18 de septiembre de 1997. SERNA, CARMEN DE LA, «José Tamayo, director y empresario de teatro: "Los políticos pasan, los artistas quedamos"», en Época, 14 de octubre de 1996, pp. 50-83.

Sin AUTOR EXPRESO, «El Teatro Lope de Vega de Educación y descanso», La Prensa, 3 de abril de 1944, p. 4.

- «Más de cien actuantes y veinte parejas de baile en la representación de "Romeo y Julieta"», La Prensa, 28 de mayo de 1945, p. 6.

- «El "Tenorio" que representará el Teatro Lope de Vega, verdadero acontecimiento artístico», La Prensa, 29 de octubre de 1945, p. 6.

- «Más de cuatro mil espectadores asistieron a las representaciones de "Romeo y Julieta"», La Prensa, 4 de junio de 1945, p. 6.

- «Un verdadero triunfo del teatro Lope de Vega con el "Tenorio"», Ideal, Granada, 2 de noviembre de 1945, p. 5.

- Ideal, 13 de febrero de 1946, p. 7.

11. En 1953 el Gobierno de España obsequió a Pío XII con la representación en el Auditorium del Palacio Pío del auto sacramental La cena del rey Baltasar, de Pedro Calderón de la Barca por la compañía Lope de Vega de José Tamayo, considerada en esos momentos como gran especialista en el género. Los papeles principales los interpretaron Francisco Rabal, José Bruguera, Manuel Dicenta, María Asunción Balaguer y Asunción Sancho. 
TAMAYO, JosÉ, «Mañana, estreno de "Nuestra ciudad" por el Teatro Universitario Lope de Vega», La Prensa, 11 de febrero de 1946, p. 4.

— «Por un teatro juvenil», Cuadernos de Teatro, 1 (1944).

TORRES, Rosana, «José Tamayo cumple hoy 50 años de profesión con el homenaje de sus amigos del teatro», en El País, 10 de octubre de 1996. 